\title{
Study of Financial Literacy and Interpersonal Influence on Self-Evaluation Bias-An Empirical Analysis with Chinese Sample
}

\author{
Xiaoyuan $\mathrm{Chu}^{1,2}$, Yuan $\mathrm{Li}^{3}$, \& Jing $\mathrm{Han}^{1}$ \\ ${ }^{1}$ School of Economics and Resource Management, Beijing Normal University, Beijing, China \\ ${ }^{2}$ School of Risk and Actuarial Studies, Business School, the University of New South Wales, Sydney, Australia \\ ${ }^{3}$ Research Department, CIConsulting, Shenzhen, China \\ Correspondence: Xiaoyuan Chu, School of Economics and Resource Management, Beijing Normal University, Beijing, \\ China.E-mail: seancxy@126.com
}

This study was supported by China Scholarship Council (No. 201506040126).

Received: August 1, 2015

doi:10.11114/ijsss.v3i6.1179
Accepted: August 25, 2015

Available online: October 30, 2015

\begin{abstract}
Based on the theoretical analysis, with first-hand data collection and using multiple regression models, this study explored the relationship between financial literacy, interpersonal influence and self-evaluation bias and figured out interactive effect of financial literacy, interpersonal influence on self-evaluation bias. We draw on the following conclusions: (1) Three financial literacy factors (sophisticated financial literacy, basic financial literacy and numeracy) entered into the regression equation on self-evaluation bias, with a predictive power of $14.8 \%$. (2) The interaction term of financial literacy and coworkers/classmates' influence can negatively predict self-evaluation bias. (3) The interaction term of financial literacy and family members' influence can negatively predict self-evaluation bias.
\end{abstract}

Keyword: financial literacy, interpersonal influence, self-evaluation bias, interaction effect

\section{Introduction}

Perception of one's own social competence derives from subjective self-evaluation of one's abilities and resources needed to deal with the various relational situations in which one may engage, and ultimately, to be accepted by others (Bandura, 1986) Self-evaluations are subject to a great deal of error resulting from self-enhancement desires and people cannot analyze themselves objectively or reliably enough to give accurate information (DeNisi \& Shaw,1977; Levine, Flory, \& Ash, 1977). People's self-perception of competence is subjective and may not accurately correspond to their real capacities (Bouffard, Vezeau, Roy, \&Lengele, 2011; Bouffard et al., 2003;). And most time, people tend to be over optimistic and their self-evaluation would exceed that predicted by their real capacities (Colvin, Block, \&Funder, 1995; Gresham, Lane, MacMillan, Bocian, \& Ward, 2000), while sometimes pessimistic bias may also occur (Strunk, Lopez \& DeRubeis, 2006; Bédard, Bouffard, \& Pansu, 2014). Sociocognitive theories suggest that people's perception of their own competence results from their actions in their environment and their interactions with significant social agents in their life (Bandura, 1986; Harter, 1990; Harter, 1992).

We can infer from the theory mentioned above that both knowledge and social influence would affect people's self-evaluation as well as accuracy of self-evaluation. However, it is how to tell exact how. In order to reveal the relationship between financial literacy, interpersonal influence and self-evaluation bias, this paper constructed a basic model as follows:

$$
\operatorname{Bias}_{i}=\beta_{0}+\sum \lambda_{1 j} \operatorname{IpIn}_{j i}+\lambda_{2} F L_{i}+\sum \lambda_{3 j} \operatorname{IpIn}_{j i} * F L_{i}+\varepsilon i
$$

In the formula, $\mathrm{i}$ represents the subjects, $\mathrm{j}$ represents the type of interpersonal influence, Bia is short for self-evaluation bias, FL is short for financial literacy, IpIn is short for interpersonal influence, IpInji*FLi is the interaction term, and $\varepsilon i$ is the error term. The same below.

\section{Methodology}

\subsection{Subjects of study}

Cluster sampling and convenient sampling methods were used for the investigation. 400 questionnaires were distributed 
in 12 corporations or institutions in Beijing, with 393 questionnaires returned and 387 valid. And another 173 questionnaires are collected from online survey, among which 162 are valid. And in total data from 549 subjects (male 318 , female 228 and 6 missing data in gender) are valid. The valid response rate is 95.81 .

\subsection{Research instrument}

Financial literacy: In this research we have used the same questionnaires used by Hazel in her research to measure financial competence (Hazel et al, 2014). There are three dimensions in financial literacy, namely numeracy, basic financial literacy and sophisticated financial literacy. In accordance with Hazel's classification, numeracy is associated with general cognition, which tests concepts such as fractions, percentages, division, multiplication and simple probability; basic financial literacy covers compound interest, inflation, time value of money and money illusion; and sophisticated financial literacy covers knowledge of the differences between bonds and stocks and the impact of risk and diversification. And financial literacy is calculated in the following formulas $F L=Z[Z(N u)+Z(B F L)+Z(S F L)$, among which $\mathrm{Z}$ is short for standard score; $\mathrm{Nu}$ is short for standard score of numeracy; BFL is short for standard score of basic financial literacy; SFL is short for standard score of sophisticated financial literacy. The same below.

Interpersonal influence: there are three dimensions in interpersonal influence: friends' influence, family members' influence and coworkers' influence or classmates' influence in this research. And each dimension includes two parts. Take friends' influence for example. Its sub-dimensions are proportion of friends who have invested in financial products and proportion of friends working in financial institution. This research applies a self-designed self-reporting questionnaire which divides proportion of friends/ family members/ coworkers or classmates who have invested in financial products into 5 grades, friends/ family members/ coworkers or classmates working in financial institution into 4 grades. And the influences of friends/ family members/ coworkers or classmates are calculated in the following formulas: FrIn=Z[Z(FrWE) $+Z($ FrIE) $]$, FaIn $=Z[Z(F a W E)+Z(F a I E)], C o I n=Z[Z(C o W E)+Z(C o I E)]$, among which FrIn is short for standard score of friends' influence; FrIE is short for standard score of proportion of friends who have invested in financial products; FrWE is short for standard score of proportion of friends working in financial institution; FaIn is short for standard score of family members' influence; FaIE is short for standard score of proportion of family members who have invested in financial products; FaWE is short for standard score of proportion of family members working in financial institution;CoIn is short for standard score of coworkers' influence or classmates' influence; CoIE is short for standard score of proportion of coworkers/classmates who have invested in financial products; CoWE is short for standard score of proportion of coworkers/classmates working in financial institution; The same below.

Self-evaluation bias: In this research, we used the discrepancy between self-evaluation of financial literacy and real financial literacy to stand for self-evaluation bias. To be specific, self-evaluation bias is calculated in the following formulas: $\mathrm{Bia}=\mathrm{Z}[|\mathrm{Z}(\mathrm{SEFL})-\mathrm{Z}(\mathrm{FL})|]$, among which SEFL is short for the score of self-evaluation of financial literacy. And we applied standard scores to ensure comparability between self-evaluation of financial literacy and real financial literacy. And application of absolute value is to ensure both over-estimate and under-estimate of competence in financial are taken into consideration.

\subsection{Research Process}

The questionnaires distributed in 12 corporations or institutions were administrated with the whole office as a group, employing group measurement under unified instructions. And the questionnaires, with no time limitation, were collected on the spot and checked one by one with invalid ones eliminated.

And the online questionnaires are distributed through email and weichat. And the subject can answer the questions with computer or cellphone with no time limitation. All the answers were collected automatically with information technology.

This research employed SPSS19.0 for statistical analysis, which includes analysis of variance, correlation analysis and analysis of regression.

\section{Results and Discussion}

\subsection{Study of influencing factors of self-evaluation bias}

3.1.1 Relationship between self-evaluation bias and demographic variables

Pearson's correlation was applied to calculate the correlation coefficients of the self-evaluation bias and demographic variables. The result is as followings:

(1) Self-evaluation bias is significantly correlated with major. Subjects majoring in economics, finance or accounting tend to be higher in self-evaluation bias;

(2) No significant correlation is found in self-evaluation bias and gender, age, marital status or education. 
Table 1. Correlation matrix of self-evaluation bias and demographic variables

\begin{tabular}{lllllll}
\hline & Bia & Gen & Age & MS & Ed & DE \\
\hline Bia & 1 & & & & & \\
Gen & .017 & 1 & & & & \\
Age & .038 & .077 & 1 & & & \\
MS & .045 & -.018 & $.658 * *$ & 1 & & \\
Ed & -.030 & $.209 * *$ & -.079 & -.050 & 1 & \\
DE & $.111 *$ & .040 & .029 & .027 & $.158^{* *}$ & 1 \\
\hline
\end{tabular}

Description: Bia is short for standard score of self-evaluation bias. SEFL is short for self-evaluation of the financial literacy. The same below.

$\mathrm{Bia}=\mathrm{Z}[|\mathrm{Z}(\mathrm{SEFL})-\mathrm{Z}(\mathrm{FL})|]$

3.1.2 Relationship between self-evaluation bias and financial literacy

Pearson's correlation was applied to calculate the correlation coefficients of the self-evaluation bias and financial literacy. The result is as followings:

Self-evaluation bias is significantly negatively correlated with financial literacy as well as all of its dimensions (numeracy, basic financial literacy and sophisticated financial literacy).

Table 2. Correlation matrix of self-evaluation bias and financial literacy

\begin{tabular}{llllll}
\hline & $\mathrm{Bia}$ & $\mathrm{FL}$ & $\mathrm{Nu}$ & $\mathrm{BFL}$ & $\mathrm{SFL}$ \\
\hline $\mathrm{Bia}$ & 1 & & & & \\
$\mathrm{FL}$ & $-.396^{* *}$ & 1 & & & \\
$\mathrm{Nu}$ & $-.258^{* *}$ & $.684^{* *}$ & 1 & & \\
$\mathrm{BFL}$ & $-.298^{* *}$ & $.744^{* *}$ & $.241^{* *}$ & 1 & \\
$\mathrm{SFL}$ & $-.305^{* *}$ & $.745^{* *}$ & $.244 * *$ & $.375^{* *}$ & 1 \\
\hline
\end{tabular}

To better understand the impact of financial literacy on self-evaluation bias, regression analysis was conducted, with self-evaluation bias as predicted variable, demographic variables (age and gender) as control variables, and financial literacy (including numeracy, basic financial literacy and sophisticated financial literacy) as predictive variable. The stepwise regression results are as followings:

Table 3. Stepwise regression analysis of personal experience on self-evaluation bias

\begin{tabular}{|c|c|c|c|c|c|}
\hline Model & Predictive variable & Standardized & $\mathrm{T}$ & $\mathrm{P}$ & Adjusted R2 \\
\hline \multirow[t]{2}{*}{1} & (constant) & & -.148 & .882 & .093 \\
\hline & SFL & -.308 & -7.470 & .000 & \\
\hline \multirow[t]{3}{*}{2} & (constant) & & -.074 & .941 & .128 \\
\hline & SFL & -.233 & -5.381 & .000 & \\
\hline & BFL & -.205 & -4.720 & .000 & \\
\hline \multirow[t]{4}{*}{3} & (constant) & & -.111 & .911 & .148 \\
\hline & SFL & -.205 & -4.721 & .000 & \\
\hline & BFL & -.179 & -4.112 & .000 & \\
\hline & $\mathrm{Nu}$ & -.154 & -3.690 & .000 & \\
\hline
\end{tabular}

As shown in the table above: three financial literacy factors (sophisticated financial literacy, basic financial literacy and numeracy) entered into the regression equation on self-evaluation bias, with a predictive power of $14.8 \%$.

3.1.3 Relationship between self-evaluation bias and interpersonal influence

Pearson's correlation was applied to calculate the correlation coefficients of the self-evaluation bias and interpersonal influence. The result is as followings: 
(1) Self-evaluation bias is significantly positively correlated with family members' influence. But the correlation coefficient is low and no correlation could be found between self-evaluation bias and either of its two dimensions (proportion of family members who have invested in financial products and proportion of family members working in financial institution);

(2) No significant correlation is found between self-evaluation bias and friends' influence or its two dimensions (proportion of friends who have invested in financial products and proportion of friends working in financial institution).

(3) No significant correlation is found between self-evaluation bias and coworkers/classmates' influence or its two dimensions (proportion of coworkers/classmates who have invested in financial products and proportion of coworkers/classmates working in financial institution).

Table 4. Correlation matrix of self-evaluation bias and interpersonal influence

\begin{tabular}{lllllllllll}
\hline & Bia & FrIn & FrIE & FrWE & FaIn & FaIE & FaWE & CoIn & CoIE & CoWE \\
\hline Bia & 1 & & & & & & & & & \\
FrIn & .019 & 1 & & & & & & & & \\
FrIE & .018 & $.832^{* *}$ & 1 & & & & & & & \\
FrWE & .013 & $.832^{* *}$ & $.385^{* *}$ & 1 & & & & & & \\
FaIn & $.096^{*}$ & $.464^{* *}$ & $.423^{* *}$ & $.349^{* *}$ & 1 & & & & & \\
FaIE & .075 & $.421^{* *}$ & $.455^{* *}$ & $.246^{* *}$ & $.823^{* *}$ & 1 & & & & \\
FaWE & .083 & $.343^{* *}$ & $.241^{* *}$ & $.329^{* *}$ & $.823^{* *}$ & $.355^{* *}$ & 1 & & & \\
CoIn & .066 & $.818^{* *}$ & $.686^{* *}$ & $.676^{* *}$ & $.456^{* *}$ & $.426^{* *}$ & $.324^{* *}$ & 1 & & \\
CoIE & .036 & $.657^{* *}$ & $.766^{* *}$ & $.327^{* *}$ & $.372^{* *}$ & $.457^{* *}$ & $.156^{* *}$ & $.810^{* *}$ & 1 & \\
CoWE & .071 & $.669^{* *}$ & $.345^{* *}$ & $.768^{* *}$ & $.365^{* *}$ & $.233^{* *}$ & $.368^{* *}$ & $.810^{* *}$ & $.312^{* *}$ & 1 \\
\hline
\end{tabular}

\subsection{Study of interaction effect of financial literacy and interpersonal influence on self-evaluation bias}

\subsubsection{Interaction effect of financial literacy and family's influence on self-evaluation bias}

In order to understand the combined effect of financial literacy and family members' influence on self-evaluation bias, regression analysis was done with self-evaluation bias as the predicted variable, financial literacy and family members' influence as predictive variables along with or without interaction term of financial literacy and family members' influence as predictive variable. The analysis result shown in table below indicates that in self-evaluation bias regression model, financial literacy has a significant interaction effect with family members' influence. In general, financial literacy helps to decrease self-evaluation bias while family members' influence fosters self-evaluation bias. However, for the subjects whose standard score of financial literacy over 0.298 , their family members' influence helps to reduce the self-evaluation bias. And for those whose standard score of family members' influence under - 1.531 , their financial literacy would promote their self-evaluation bias.

Table 5. Interaction effect of financial literacy and family's influence on self-evaluation bias

\begin{tabular}{llcc}
\hline & Standardized regression equation & Adjusted R2 & Increase in R2 \\
\hline First-step & Bia=-0.395FL+0.093FaIn & 0.163 & \\
Second-step & Bia=-0.349FL+0.068FaIn-0.228FL*FaIn & 0.211 & $0.048^{* *}$ \\
\hline
\end{tabular}

$\mathrm{Bia}=-0.349 \mathrm{FL}+0.068 \mathrm{FaIn}-0.228 \mathrm{FL} * \mathrm{FaIn}=-0.349 \mathrm{FL}+(0.068-0.228 \mathrm{FL}) \mathrm{FaIn}=0.068 \mathrm{FaIn}-(0.349+0.228 \mathrm{FaIn}) \mathrm{FL}$

\subsubsection{Interaction effect of financial literacy and coworkers/classmates' influence on self-evaluation bias}

In order to understand the combined effect of financial literacy and coworkers/classmates' influence on self-evaluation bias, regression analysis was done with self-evaluation bias as the predicted variable, financial literacy and coworkers/classmates' influence as predictive variables along with or without interaction term of financial literacy and coworkers/classmates' influence as predictive variable. The analysis result shown in table below indicates that in self-evaluation bias regression model, financial literacy has a significant interaction effect with coworkers/classmates' influence. In general, financial literacy helps to decrease self-evaluation bias while coworkers/classmates' influence fosters self-evaluation bias. However, for the subjects whose standard score of financial literacy over 1.211, their coworkers/classmates' influence helps to reduce the self-evaluation bias. And for those whose standard score of coworkers/classmates' influence under -3.706 (which is quite rare and can be ignored), their financial literacy would promote their self-evaluation bias. 
Table 6. Interaction effect of financial literacy and coworkers/classmates' influence on self-evaluation bias

\begin{tabular}{llcc}
\hline & Standardized regression equation & Adjusted R2 & Increase in R2 \\
\hline First-step & Bia $=-0.417 \mathrm{FL}+0.131 \mathrm{CoIn}$ & 0.171 & \\
Second-step & Bia $=-0.404 \mathrm{FL}+0.132 \mathrm{CoIn}-0.109 \mathrm{FL} *$ CoIn & 0.181 & $0.010 * *$ \\
\hline
\end{tabular}

$\mathrm{Bia}=-0.404 \mathrm{FL}+0.132 \mathrm{CoIn}-0.109 \mathrm{FL} * \mathrm{CoIn}=-0.404 \mathrm{FL}+(0.132-0.109 \mathrm{FL}) \mathrm{CoIn}=0.132 \mathrm{CoIn}-(0.404+0.109 \mathrm{CoIn}) \mathrm{FL}$

\section{Conclusion}

Basing on the above analysis and discussion, a summary of the conclusion are as follows:

(1) Three financial literacy factors (sophisticated financial literacy, basic financial literacy and numeracy) entered into the regression equation on self-evaluation bias, with a predictive power of $14.8 \%$.

(2) Financial literacy has a significant interaction effect with coworkers/classmates' influence in self-evaluation bias regression model.

(3) Financial literacy has a significant interaction effect with family members' influence in self-evaluation bias regression model.

\section{Reference}

Bandura, A. (1986) Social foundations of thought and action: A social cognitive theory. Prentice-Hall, Englewood, NJ

Bateman, H., Eckert, C., Geweke, J., Louviere, J., Satchell, S., \& Thorp, S. (2014). Financial competence, risk presentation and retirement portfolio preferences. Journal of Pension Economics and Finance, 13(1), 27-61. http://dx.doi.org/10.1017/S1474747213000188

Bouffard, T., Boisvert, M., \& Vezeau, C. (2003). The illusion of incompetence and its correlates among elementary school children and their parents. Learning and Individual Differences, 14, 31-46. doi:10.1016/j.lindif.2003.07.001 http://dx.doi.org/10.1016/j.lindif.2003.07.001

Bouffard, T., Vezeau, C., Roy, M., \& Lengele, A. (2011). Stability of biases of self-evaluation andrelations to well-being in elementary school children. International Journal of Educational Research, 50, 221-229. http://dx.doi.org/10.1016/j.ijer.2011.08.003

Colvin, C. R., Block, J., \& Funder, D. C. (1995). Overly positive evaluations and personality: Negative implications for mental health. Journal of Personality and Social Psychology, 68, 1152-1162. http://dx.doi.org/10.1037/0022-3514.68.6.1152

DeNisi, A. S., \& Shaw, J. B. (1977). Investigation of the uses of self-reports of abilities. Journal of Applied Psychology, 62, 641-644. http://dx.doi.org/10.1037/0021-9010.62.5.641

Strunk, D. R., Lopez, H., DeRubeis, R. J. (2006).Depressive symptoms are associated with unrealistic negative predictions of future life events, Behavior research and therapy, 44(6), 861-882. http://dx.doi.org/10.1016/j.brat.2005.07.001

Gresham, F. M., Lane, K. L., MacMillan, D. L., Bocian, K. M., \& Ward, S. L. (2000). Effects of positive and negative illusory biases: Comparisons across social and academic self-concept domains. Journal of School Psychology, 38, 151-175. http://dx.doi.org/10.1016/S0022-4405(99)00042-4

Harter, S. (1990). Causes, correlates, and the functional role of global self-worth: A life-span perspective. In R. J. Sternberg \& J. Kolligian Jr (Eds.), Competence considered , 67-98.New Haven, CT: Yale University Press.

Harter, S. (1992). The relationship between perceived competence, affect, and motivational orientation within the classroom: Processes and patterns of change. In A. K. Boggiano (Ed.), Achievement and motivation: A social developmental perspective, 77-114. New York, NY: Cambridge University Press.

Bédard, K., Bouffard, T., \& Pansu, P. (2014). The risks for adolescents of negatively biased self-evaluations of social competence: The mediating role of social support. Journal of adolescence, 37(6), 787-798 http://dx.doi.org/10.1016/j.adolescence.2014.05.004

Levine, E. L., Flory, A., \& Ash, R. A. (1977). Self-assessment in personnel selection. Journal of Applied Psychology, 62, 428-435. http://dx.doi.org/10.1037/0021-9010.62.4.428

\section{(cc) BY}

This work is licensed under a Creative Commons Attribution 3.0 License. 